\title{
Evolutionary Profile of Cellulitis and Erysipelas of Lower Limbs in a Level-Two Healthcare Facility in Brazzaville, Congo
}

\author{
Edith Sophie Bayonne-Kombo 1, 2, *, Axel Gillius Aloumba ${ }^{1,3}$, Aude Kanga Okandzé2, \\ Yanichka Voumbo-Mavoungou ${ }^{2}$, Alphonse Gathsé ${ }^{1}$ \\ ${ }^{1}$ Department of Medicine, Faculty of Health Sciences, Marien Ngouabi University, Brazzaville, Congo \\ ${ }^{2}$ Department of Dermatology and Infectious Diseases, Talangaï Reference Hospital, Brazzaville, Congo \\ ${ }^{3}$ Department of Infectious Diseases, Teaching Hospital, Brazzaville, Congo
}

Email address:

sophiekbb@outlook.com (E. S. Bayonne-Kombo), axel.aloumba@gmail.com (A. G. Aloumba), kangaok@gmail.com (A. K. Okandzé), gvoumbo@gmail.com (Y. Voumbo-Mavoungou), alphonse.gathse@gmail.com (A. Gathsé)

${ }^{*}$ Corresponding author

\section{To cite this article:}

Edith Sophie Bayonne-Kombo, Axel Gillius Aloumba, Aude Kanga Okandzé, Yanichka Voumbo-Mavoungou, Alphonse Gathsé. Evolutionary Profile of Cellulitis and Erysipelas of Lower Limbs in a Level-Two Healthcare Facility in Brazzaville, Congo. International Journal of Infectious Diseases and Therapy. Vol. 5, No. 1, 2020, pp. 4-8. doi: 10.11648/j.ijidt.20200501.12

Received: January 24, 2020; Accepted: February 12, 2020; Published: February 19, 2020

\begin{abstract}
Background: Cellulitis/erysipelas are the most frequent reason for hospitalization in dermatology departments. Objective: To describe evolutionary profile of cellulitis/erysipelas and to determine associated factors with the long hospital stay. Methods: This was a cross-sectional study carried out from January 2016 to December 2018 in Talangaï Reference Hospital, that included patients hospitalized for cellulitis or erysipelas of the lower limbs. Necrotizing fasciitis cases were excluded. A hospital stay of more than 11 days was considered long. Sociodemographic, clinical and biological data were collected and processed with Epi Info 7.2.1.0. The Chi-square and Fisher tests were used for univariate analysis. Logistic regression was used for multivariate analysis. Results: One hundred and five patients were included, with an average age of $50.7( \pm 15)$ years. They were $26(24.8 \%)$ men and 79 (74.2\%) women. Antibiotic regimen used was amoxicillin in 19 (18.1\%) cases, amoxicillin / clavulanic acid in 40 (38.1\%) cases and ceftriaxone in $46(43.8 \%)$ cases. The outcome was favorable in $69(65.7 \%)$ patients. Fever persisted after 5 days-treatment in $19(28.3 \%)$ patients out of 67 initially. Complications were cutaneous necrosis in $19(18.0 \%)$ cases, abscess in 14 (13.3\%) cases, severe sepsis and necrotizing fasciitis in 7 and 4 cases, respectively. Two patients died. The average length of hospital stay was 13 days ( \pm 7.5$)$ and 44 (41.9\%) cases had a long hospital stay. The bullous forms of cellulitis/erysipelas [aOR=4.8, 95\%CI (1.9-12.4); $p=0.001]$ and the occurrence of complications $[\mathrm{aOR}=3.2,95 \% \mathrm{CI}(1.1-8.7) ; p=0.026]$ were associated with a long hospital stay. Conclusion: Cellulitis and erysipelas are potentially serious. Despite treatment, complications can occur, including necrosis and abscess. Effective management, including early medical treatment, daily thorough monitoring of patients, appropriate local care and collaboration with surgeons, is necessary to improve the prognosis of the disease.
\end{abstract}

Keywords: Cellulitis, Erysipelas, Complication, Abscess, Hospitalization, Congo

\section{Introduction}

Cellulitis is an infection of the dermis and hypodermis, manifested by a poorly demarcated erythema, edema and warmth [1]. Erysipelas is a superficial form of cellulitis mainly affecting dermis and involving less the hypodermis, presenting with well demarcated erythema and edema [2, 3]. The historical distinction between cellulitis and erysipelas, based on different bacterial aetiologies and their treatment options, is becoming obsolete [3]. Several studies suggest a great overlap of the bacteria involved between these two entities $[4,5]$.

Cellulitis is the most frequent reason of hospitalization for infectious skin diseases in developed and developing countries [6-8]. Medical care must be effective early to avoid complications. Treatment is mainly based on antibiotic 
therapy and local care in some cases. Despite published guidelines, the treatment regimens used are various [1]. Most cases of cellulitis are successfully treated with antibiotics, but complications can occur, such as abscess formation, skin necrosis, necrotizing fasciitis and sepsis during the acute period. The short-term complications of cellulitis and erysipelas can be responsible for long hospital stays.

Cellulitis comes to be a major problem in term of morbidity and length of hospital stay [9]. The long hospital stay leads to considerable financial costs worldwide [10]. In order to improve the management of cellulitis/erysipelas, our study aimed to describe the evolutionary profile of cellulitis/erysipelas of lower limbs and to determine the associated factors with long hospital stays in a level-two healthcare facility, in Brazzaville (Congo).

\section{Patients and Methods}

\subsection{Study Design}

This was an analytical cross-sectional study, carried out from January 2016 to December 2018 in Dermatology and Infectious Diseases Department of Talangaï Reference Hospital in Brazzaville, Congo. The Talangaï Reference Hospital is a second-level health care facility, according to health system in Congo, and it is a first-line referral hospital for dermatological problems.

\subsection{Patients Selection}

The study population consisted of patients with cellulitis or erysipelas and hospitalized in Dermatology and Infectious Diseases Department. Patients with cellulitis or erysipelas located on lower limbs were included. Patients with primary necrotizing fasciitis were excluded. The diagnosis of cellulite and erysipelas was based on clinical criteria. The term cellulite used in our study refers to one of the clinical forms, either cellulite or erysipelas.

\subsection{Variables}

Data were collected from medical records at the end of each hospitalization. Study variables were demographic, clinical, and biological data. Demographic data were age, sex and occupation. The clinical data were the following: previous history of cellulitis, the consultation period (time between onset of symptom and admission), medical practices used prior to admission, comorbidity (obesity, high blood pressure, liver failure, renal failure, lymphoedema), cosmetic practices, systemic symptoms, clinical type, location of cellulitis, treatment, outcomes and length of hospital stay (LHS). A duration of hospital stay longer than 11 days was defined as long. The biological data were white blood cells (WBC) count and neutrophils, $\mathrm{C}$ reactive protein (CRP), aspartate aminotransferase, alanine aminotransferase, creatinine and blood urea.

\subsection{Data Management}

The collected data were entered into a database created with the Epi Info software Version 7.2.1.0 (Center for Disease Control and Prevention, Atlanta, GA). The data processing and statistical analysis were performed using Epi Info software.

Quantitative data were expressed as mean and standard deviation (SD). Qualitative data were expressed in number and frequency (percentage). Univariate analysis was performed to identify variables associated with long hospital stay. Data were analyzed using chi-square test and Fisher's test as appropriate. The outcome variable was a "long hospital stay". Multivariate regression analysis was performed in a second step to determine independent associated factors and adjusted Odds ratio (aOR). The significance was considered for a $p$-value less than 0.05 for a $95 \%$ confidence interval (CI).

\section{Results}

\subsection{Characteristics of Study Population}

A total of 105 patients hospitalized for cellulitis was included. They were 26 (24.8\%) men and 79 (75.2\%) women. The mean age was $50.4( \pm 15)$ years. Four women were pregnant. A previous history cellulitis was found in 19 (18.1\%) cases. The average consultation period was $6( \pm 5)$ days. Forty-two $(40.0 \%)$ patients used non-steroidal anti-inflammatory drugs (NSAIDs) prior to admission and 24 $(22.9 \%)$ used antibiotics. The general characteristics of study population are showed in Table 1.

Table 1. General characteristics of study population.

\begin{tabular}{ll}
\hline Characteristics & Distribution N=105 n (\%) \\
\hline Comorbid factors & \\
Obesity (BMI >30) & $15(14.3)$ \\
Diabetes & $12(11,4)$ \\
High Blood Pressure (HBP) & $30(28,6)$ \\
Lymphoedema & $13(12.4)$ \\
Renal failure & $6(5.7)$ \\
Depigmenting cosmetic practice & $18(17.1)$ \\
Fever & $67(63.8)$ \\
Clinical subtype & \\
Erythematous & $48(45.7)$ \\
Erythematous and purpuric & $3(2.7)$ \\
Erythematous and bullous & $49(46.7)$ \\
Necrotizing & $5(4.8)$ \\
Location & $1(0.9)$ \\
Thigh & $75(71.4)$ \\
Leg & $20(19.1)$ \\
Leg and foot & $9(8.6)$ \\
All the lower limb & $40(38.1)$ \\
Neutrophils $>12000 / \mu 1$ & $47(44.8)$ \\
CRP $>48$ mg/L & $19(18.1)$ \\
Antibiotic regimen & $40(38.1)$ \\
Amoxicillin & $25(23.8)$ \\
Amoxicillin/ Clavulanic acid & $21(20.0)$ \\
Ceftriaxone & \\
Ceftriaxone/ Gentamycin & \\
\hline
\end{tabular}

$\mathrm{BMI}=$ Body mass index, $\mathrm{HBP}=$ High blood pressure, $\mathrm{CRP}=\mathrm{C}$-reactive protein .

\subsection{Evolutionary Profile}

Fever persisted after 5 days-treatment in 19 (28.3\%) 
patients out of 67 initially. Among the 105 patients with cellulitis, $69(65.7 \%)$ had a regression of the disease, 32 (30.5\%) developed complications and 4 patients were discharged from the hospital before improvement without medical consent. Complications showed in Table 2 were sometimes combined in the same patient.

Table 2. Complications of cellulite in 105 hospitalized patients.

\begin{tabular}{ll}
\hline Characteristics & Distribution n (\%) \\
\hline Cutaneous necrotizing & $19(18,0)$ \\
Abscess formation & $14(13.3)$ \\
Necrotizing fasciitis & $7(6.7)$ \\
Severe sepsis & $4(3.8)$ \\
\hline
\end{tabular}

Of the patients who developed necrotizing complications, six were transferred to the surgical department. For the other cases, care was carried out in Dermatology and Infectious Diseases Department in collaboration with the surgeons.

Two patients died from severe sepsis.

The average duration of hospital stay was $13( \pm 7,5)$ days. The median length of hospital stay was 10 days.

\subsection{Factors Associated with Long Hospital Stays}

Of all cases, $44(41.9 \%)$ patients had a hospital stay more than 11 days. Table 3 shows the factors associated with a long hospital stay in univariate analysis.

Table 3. Associated factors with long hospital stay in 105 hospitalized patients, in univariate analysis.

\begin{tabular}{|c|c|c|c|c|}
\hline \multirow[t]{2}{*}{ Variable } & \multicolumn{2}{|c|}{ Long hospital } & \multirow{2}{*}{ OR 95\% CI } & \multirow{2}{*}{ p-value } \\
\hline & Yes, n (\%) & No, n (\%) & & \\
\hline \multicolumn{5}{|l|}{ Diabetes } \\
\hline Yes & $8(66.7)$ & $4(33.3)$ & $3.1[0.7-15.3]$ & 0.063 \\
\hline No & $36(38,7)$ & $57(51,3)$ & & \\
\hline \multicolumn{5}{|c|}{ High Blood pressure } \\
\hline Yes & $11(36.7)$ & $19(63.3)$ & $0.7[0.2-1.9]$ & 0.321 \\
\hline No & $33(44,0)$ & $42(56,0)$ & & \\
\hline \multicolumn{5}{|c|}{ Lymphoedema } \\
\hline Yes & $5(38.5)$ & $8(61.5)$ & $0.8[0.2-3.2]$ & 0.517 \\
\hline No & $39(42,4)$ & $53(57,1)$ & & \\
\hline \multicolumn{5}{|c|}{ Obesity $(\mathrm{BMI}>30)$} \\
\hline Yes & $10(66.7)$ & $5(33.3)$ & $3.3[0.9-13.2]$ & 0.030 \\
\hline No & $34(37,8)$ & $56(62,2)$ & & \\
\hline \multicolumn{5}{|c|}{ NSAIDs use } \\
\hline Yes & $21(50.0)$ & $51(50.0)$ & $1.7[0.7-4.1]$ & 0.120 \\
\hline No & $23(36,5)$ & $40(63,5)$ & & \\
\hline \multicolumn{5}{|c|}{ Bullous forms of cellulitis } \\
\hline Yes & $32(65.3)$ & $17(34.7)$ & $6.7[2.6-18.1]$ & $<0.001$ \\
\hline No & $12(21,4)$ & $44(78,6)$ & & \\
\hline \multicolumn{5}{|c|}{ Complications } \\
\hline Yes & $21(65.6)$ & $11(34.4)$ & $4.0[1.5-11.1]$ & 0.001 \\
\hline No & $23(31,5)$ & $50(68,5)$ & & \\
\hline \multicolumn{5}{|c|}{ Neutrophils count $>12000 / \mathrm{mL}$} \\
\hline Yes & $24(60.0)$ & $16(40.0)$ & $3.3[1.7-8.3]$ & 0.003 \\
\hline No & $20(30,8)$ & $45(69,2)$ & & \\
\hline \multicolumn{5}{|c|}{$\mathrm{CRP}>48 \mathrm{mg} / \mathrm{L}$} \\
\hline Yes & $24(51.0)$ & $23(49.0)$ & $1.9[0.9-13.2]$ & 0.030 \\
\hline No & $20(34,5)$ & $38(65,5)$ & & \\
\hline
\end{tabular}

$\mathrm{BMI}=$ Body mass index, NSAIDs=non-steroidal anti-inflammatory drugs.

The factors associated with long hospital stays in multivariate analysis were Bullous forms of cellulitis and the occurrence of complications (Table 4).

Table 4. Associated factors with long hospital stays in 105 hospitalized patients, in multivariate analysis.

\begin{tabular}{lll}
\hline Variable & aOR 95\% CI & p-value \\
\hline Obesity $(\mathrm{BMI}>30$ & $2.4[0.6-9.0]$ & 1.192 \\
Bullous forms & $4.8[1.9-12.4]$ & 0.001 \\
Complications & $3.1[1.1-8.7]$ & 0.026 \\
Neutrophils $>12000 / \mu 1$ & $1.3[0.5-3.7]$ & 0.551 \\
\hline
\end{tabular}

$\mathrm{BMI}=$ Body mass index.

\section{Discussion}

This study aimed to determine evolutionary profile of cellulitis and to identify associated factors with long hospital stay. The choice of 11 days to determine the long hospital stay was based on the operational definitions of level-two healthcare facilities.

One of the limitations of this study is the monocentric character. Indeed, a larger study also including internal medicine departments would be of great interest. The other limitation is the retrospective nature of the data collection. Data collection was continuous over the three years of the study, but it was carried out after discharge. However, all the patients were examined by a dermatological specialist and the medical records correctly informed the condition of patients.

The length of hospital stay exceeded 11 days for $41.9 \%$ of patients. The average length and median of hospital stay were 13 and 10 days respectively. A previous study at Teaching 
Hospital of Brazzaville reported a length of hospital stay between 21 and 30 days [11]. Studies in sub-Saharan Africa report varying values. In Senegal, in a study of 194 cases, the average LHS was 14.6 days [12]. In Togo, the LHS was 21 days in a series of 104 cases, but which included necrotizing fasciitis [13]. A study in Morocco reported an average LHS of 15 days in a series of 100 cases [14]. In France and Portugal, the hospital stays for cellulitis reported are 11 days for the respective series of 111 and 348 patients $[15,16]$. In Cameroon, the median duration was 14 days [17]. Cellulitis is an acute infectious disease needed to be treated efficiently and the hospital stay must be as short as possible. What's more, lower-limbs location exposes to complications of decubitus. A long hospital stay can be an economic burden for affected families when there is no funding for health care. In Congo, patients who are hospitalized in a level-2 hospital have no social care. They fund their care themselves, including drug costs and hospital stay fees. Lengthy hospital stays also affect the professional activities of individuals. Indeed, all income-generating activities are stopped during the hospitalization period.

Despite the treatment, $30.5 \%$ of patients developed complications. The most common complication was the occurrence of skin necrosis. It is often difficult to distinguish from an initial necrotizing soft tissue infection that was underdiagnosed. In necrotizing soft tissue infection, cutaneous necrosis progresses rapidly a few hours after the onset of erythema and edema of limb [18]. An appropriate daily examination of patients leads to early diagnosis of necrotizing soft tissue infection. At Teaching Hospital of Brazzaville, another study of 54 cellulitis patient reported complications in $77.7 \%$ of cases [19]. Among these, skin necrosis was found in $73.8 \%$ of cases [19]. Necrosis require surgical debridement care which exacerbates ulceration. Health care professionals providing cellulitis care must monitor the appearance of this complication. The abscess formation is the second complications found in $13.3 \%$ of our patients. It is close to the finding of a multicenter study in 8 countries in sub-Saharan Africa (11.2\%) and in Morocco (11\%) [20, 21]. These sub-Saharan African countries were Togo, Senegal, Mali, Côte d'Ivoire, Guinea, Burkina Faso, Central African Republic and Cameroon [20]. In Greece, abscess was found in $17 \%$ of cellulite cases [22]. Abscess formation was less frequent (8\%) in a study in France [23]. The diagnosis of the abscess should be early and suspected if the pain and fever persist. Examination of the leg in search of fluctuation may be supplemented by imaging tools. Other complications of cellulite have been observed in Senegal [12]. These were myositis and osteitis.

Our study identified the bullous form of cellulitis and the occurrence of complications as associated factors with long hospital stays. The bullae are generally consecutive to the edema associated with erythema in patients with cellulitis. They lead to the formation of ulcers. The length of hospital stay depends on the healing process of post-bullous ulcers. Other factors associated with long hospital stays were identified in various studies. Roda found that occurrence of complications, increased age, previous episode of cellulitis/erysipelas, high level of CRP and leukocytosis are associated factors with LHS [16]. Mascitti found diabetes, obesity $(\mathrm{BMI}=28)$, immunosuppression and leucocytosis greater than $13000 / \mu 1$ as associated factors [15]. In Morroco, Titou found that days of hospitalization were increased in patients with complicated erysipelas [21]. In the New Zealand, Morpeth found that use of diuretics, neutrophil count $>10 \times 10$ (9)/l and extended edema were associated with long hospital stay [24]. Our study did not show a significant association with leukocytosis greater than $12000 / \mathrm{mL}$ or obesity in multivariate analysis. The association with immunosuppression had not been analyzed because not all patients had been assessed on their immunity. In Australia, Aly found that lengthy stays for lower-limbs cellulitis in a tertiary teaching hospital were associated with surgical intervention or intercurrent problems [25]. He also found that $15 \%$ of patients remained in hospital longer than 10 days for no clear indication [25].

In our study, four patients were discharged from the hospital without medical consent. In our society, this practice is sometimes observed when patients believe in a metaphysical origin of a disease. These beliefs are called "mouandza" in popular language. In these situations, patients go to traditional healers and refuse modern care.

Our observations show the need for a daily evaluation of hospitalized patients with cellulitis. Initial bullae or their appearance during evolution requires adequate local care to limit secondary ulcers. The daily examination also aims to detect complications early to ensure their management.

\section{Conclusion}

Cellulitis and erysipelas are potentially serious. Despite treatment, complications can occur of which necrosis and abscess are most frequent. Hospitalization is lengthy in almost of the cases. Bullous forms of cellulitis/erysipelas and the occurrence of complications are associated factors with long hospital stays. Management of cellulitis/erysipelas need early medical treatment and daily thorough monitoring of patients. Effective management of complications, including careful local care and collaboration with surgeons, is necessary to reduce the burden of illness of cellulitis and erysipelas.

\section{Abbreviations}

$\begin{array}{ll}\text { aOR } & \text { Adjusted Odds Ratio } \\ \text { BMI } & \text { Body mass index } \\ \text { CI } & \text { Confidence interval } \\ \text { CRP } & \text { C reactive protein } \\ \text { HBP } & \text { High blood pressure } \\ \text { LHS } & \text { Length of hospital stay } \\ \text { NSAIDs } & \text { Non-steroidal anti-inflammatory drugs } \\ \text { OR } & \text { Odd Ratio } \\ \text { SD } & \text { Standard Deviation } \\ \text { WBC } & \text { White blood count }\end{array}$




\section{Conflicts of Interest}

None.

\section{Funding}

None.

\section{Ethical Approval and Consent for Participation}

The study was not carried out directly on human subjects.

\section{Acknowledgements}

We acknowledge the management team of Talangaï Reference Hospital.

\section{References}

[1] Raff, A. B. and Kroshinsky, D (2016). Cellulitis. A Review. JAMA 316 (3): 325-337.

[2] Bonnetblanc, J. M. and Bedane, C (2003). Erysipelas. Recognition and Management. Am J Clin Dermatol 4 (3): 157-163.

[3] Cranendonk, D. R., Lavrijsen, A. P. M., Prins, J. M. and Wiersinga, W. J (2017). Cellulitis: current insights into pathophysiology and clinical management. Neth J Med 75 (9): 366-378.

[4] Blackberg, A., Trell, K. and Rasmussen, M (2015). Erysipelas, a large retrospective study of aetiology and clinical presentation. BMC Infect Dis 15: 402.

[5] Gunderson, C. G. and Martinello, R. A (2012). A systematic review of bacteremias in cellulitis and erysipelas. J Infect 64 : 148-155.

[6] Christensen, K. L., Holman, R. C., Steiner, C. A., Sejvar, J. J., Stoll, B. J. and Schonberger, L. B (2009). Infectious disease hospitalizations in the United States. Clin Infect Dis 49: 1025-1035.

[7] Lamchahab, F. E., Beqqal, K., Guerrouj, B., Khoudri, I., Senouci, K., Hassam, B et al (2010). Bilan d'hospitalisation du service de dermatologie-vénérologie du CHU Ibn Sina Rabat Maroc. Pan Afr Med J 7: 17.

[8] Keita, M., Koulibaly, M., Soumah, M. M., Diané, B., Tounkara, T. M., Camara, A. D. et al (2014). Morbidité et mortalité hospitalières dans le service de dermatologie-MST du CHU de Conakry (Guinée). Ann Dermatol Venereol 141 (12) Suppl: S356-S357.

[9] Sartelli, M., Guirao, X., Hardcastle, T. C., Kluger, Y., Boermeester, M. A., Raşa, K et al (2018). 2018 WSES/SIS-E consensus conference: recommendations for the management of skin and soft-tissue infections. World J Emerg Surg 13: 58.

[10] Goettsch, W. G., Bouwes Bavinck, J. N. and Hering R. M. C. (2006). Burden of illness of bacterial cellulitis and erysipelas of leg in the Netherlands. J Eur Acad Dermatol Venereol 20: 834-839.
[11] Gathsé A, Obengui, Ntsiba H 2006. Retrospective study of 53 erysipelas cases in Brazzaville university hospital, Congo [Etude retrospective de 53 érysipèles hospitalisés au CHU de Brazzaville, Congo]. Bull Soc Pathol Exot 99 (1): 3-4

[12] Diédhiou, D., Lèye, M. M. M., Touré, M., Boiro, D., Sow, D., Lèye, Y. M. et al (2013). Dermohypodermite bactérienne à Dakar: retrospective de 194 cas suivis en médecine interne à la Clinique médicale II. Rev Cames Santé 1 (1): 31-35.

[13] Saka, B., Kombaté, K., Mouhari-Touré, A., Akakpo, S. Boukari, T., Pitché, P et al (2011). Dermo-hypodermites bactériennes et fasciitis nécrosantes: 104 observations au Togo. Med Trop 71: 162- 164 .

[14] Amal, S., Houass, S., Laissaoui, K., Moufid, K., Trabelsi, M (2004). Epidemiology, clinical features, and evolution of Erysipelas in the Marrakech region (100 cases). Med Mal Infect 34: 171-176.

[15] Mascitti H, Dinh A., Tourte M., Duran C., Hanslik T., Perronne C. et al (2019). Identification des facteurs de risque de non-réponse précoce des érysipèles hospitalisés. Ann Dermatol Venereol 146 (12) Suppl: a118-a119.

[16] Roda Â., Pinto A. M., Filipe A. R., Travassos A. R., Freitas J. P and Filipe P (2019). Clinical and laboratory factors associated with prolonged hospital stay among patients with cellulitis/erysipelas. Acta Medica Portuguesa, 32 (6): 448-452.

[17] Njim, T., Ndemnge Aminde, L., Ndip Agbor, V., Toukam, L. D., Kashaf, S. S., Ohuma, E. D (2007). Risk factors of lower limb cellulitis in a level-two healthcare facility in Cameroon: a case-control study. BMC Infect Dis 17: 418.

[18] Mishra, S. P., Singh, S. and Gupta, S. K. (2013). Necrotizing soft tissue infections: Surgeon's prospective. Int J Inflam Vol 2013, Article ID 609628, 7 pages. http://dx.doi.org/10.1155/2013/609628

[19] Lenga Loumingou, I. A., Loumongou, J. R., Soussa, R. and Gathsé, A (2013). Complications des érysipèles au C. H. U de Brazzaville. Ann Univ M Ngouabi 14 (5): 55-60.

[20] Pitché, P. V., Saka, B., Diatta, A. B., Faye, O., Diané, B. F., Sangaré, A. et al (2015). Risk factors associated with abscesse formation among patient with leg erysipelas (cellulitis) in sub-saharan Africa: a multicenter study. BMC Dermatology 15: 18 .

[21] Titou, H., Ebongo, C. C., Bouati, E, and Boui, M (2017). Factors associated with local complications of erysipelas: retrospective study of 152 cases. Pan Afr Med J 16: 66.

[22] Krasagakis, K., Samonis, G. Valachis, A., Maniatakis, P., Evangelou, G and Tosca, A (2011). Local complications of erysipelas: a study of associated risk factors. Clin Exp Dermatol 36: 351-354.

[23] Picard, D., Klein, A., Grigioni, S., Joly and P (2013). Risk factors for abscess formation in patients with superficial cellulitis (erysipelas) of leg. Br J Dermatol 168: 859-863.

[24] Morpeth, S. C., Chambers, S. T., Gallagher, K., Frampton, C. and Pithie, A. D (2006). Lower limb cellulitis: features associated with length of hospital stay. J Infect 52 (1), 23-29.

[25] Aly, A. A., Roberts, N. M., Seipol, K. S. and MacLellan, D. G (1996). Case survey of management of cellulitis in a Tertiary Teaching Hospital. Med J Aust 165 (10), 553-556. 